\title{
Tree-ring reconstructions of circulation indices
}

\author{
Connie A. Woodhouse* \\ Laboratory of Tree-Ring Research, The University of Arizona, Tucson, Arizona 85721, USA
}

\begin{abstract}
Generalized circulation indices, as descriptors of atmospheric circulation features, have been used to analyze the relationships between circulation and regional climates. Currently, data for such circulation indices are limited. Records for some indices extend back into the 19th century, but most are based on data that exist for less than $100 \mathrm{yr}$. Tree rings have been successfully used to extend records of circulation indices, most notably the Southern Oscillation Index. Researchers are continuing to improve reconstructions and to explore the potential of reconstructing other indices. In contrast to more general indices, it is possible to select and/or construct indices that describe circulation features important to a specific region. These regionally tailored circulation indices, along with more general indices that describe features also influencing the climate of a region, can be reconstructed from tree rings. Reconstructions can provide information about variability in atmospheric circulation and about the interactions between influential circulation features in past centuries. In this paper, an example of such a study is given in which a set of circulation indices, compiled for the southwestern U.S., is reconstructed from tree rings. This preliminary study demonstrates the potential value of regionally tailored circulation indices and the reconstruction of these circulation indices for gaining an understanding of how circulation patterns may influence regional climates, on scales of decades to centuries.
\end{abstract}

KEY WORDS: Circulation indices - Tree rings Climate reconstructions - Southwestern U.S.

\section{INTRODUCTION}

While it has long been recognized that hemisphericto global-scale circulation features influence regional climates, researchers recently have been reminded of the severity of the impacts these features can have on regional climates, and in turn, the populations, welfare, and economies of the affected regions. The 198283 El Niño event was the most severe that has been observed in the 20th century, with impacts on climate in many parts of the world (Kiladis \& Diaz 1986). This event has emphasized the need for a better understanding of the relationships between regional climates and large-scale atmospheric circulation features.

Indices offer a way to analyze the relationships between a circulation feature and other time series that describe regional climates. A circulation index is a

\footnotetext{
- Current affiliation: NOAA Paleoclimatology Program. NGDC, 325 Broadway, Boulder, Colorado 80303, USA.

E-mail:woodhous@ngdc.noaa.gov
}

time series that describes an atmospheric condition and the variations in that condition over time. An index usually synthesizes some key aspect of circulation, often over a large area such as an ocean or continent. It may describe contrasting effects or teleconnections, or mechanisms that work together to produce an overall effect. Indices are particularly useful because they extract the quintessence of a circulation feature into a single time series that can then be used in analyses with other climate and circulation time series, or as a basis for reconstructing the circulation feature described by the index.

Indices have been used to describe features of the El Niño/Southern Oscillation (ENSO). ENSO is recognized as a dominant oceanic/atmospheric circulation mechanism influencing interannual climate variability in areas such as Australia, Indonesia, South Asia, southeastern Africa, Ethiopia, northeastern Brazil, Chile, Argentina, Uruguay, and the southern United States (Diaz \& Kiladis 1992). The oscillations in ENSO result in a set of characteristic oceanic and atmospheric circulation responses. Circulation features that are manifesta- 
tions of variations in ENSO include oscillations in sea level pressure between Tahiti and Darwin, Australia (the Southern Oscillation), variations of sea surface temperature (SST) in the equatorial Pacific, and the varying strength of zonal winds across the equatorial Pacific. These features can be depicted through the use of indices, such as the Southern Oscillation Index (SOI), the Niño3 index, and a $200 \mathrm{mb}$ zonal wind index (see, for example, the Climate Diagnostics Bulletin published by the Climate Prediction Center, U.S. Department of Commerce, Washington, DC).

Other hemispheric- to global-scale circulation patterns have been found to affect regional climates around the world, and have been characterized by circulation indices as well. Two of the most notable of these patterns are the Pacific/North American (PNA) pattern (Wallace \& Gutzler 1981) and the North Atlantic Oscillation (NAO). The PNA pattern, which is sometimes associated with ENSO (Yarnal \& Diaz 1986) is one of most important modes of atmospheric circulation in winter over North America (Simmons et al. 1983, Barnston \& Livezey 1987). The NAO, identified by Walker \& Bliss (1932), is an important basis of winter climate variability in the North Atlantic and western Europe and the Mediterranean (Wallace \& Gutzler 1981).

These and other atmospheric circulation features have great impacts upon climate. A knowledge of the impacts allows us to understand causes of climate variability - changes in means as well as extremes-and the ways in which regional climates are related to atmospheric circulation patterns. Currently, the data available for circulation indices are limited. Although a few records, such as those for the SOI and the NAO index, extend back into the 19th century (Wright 1989, Hurrell 1995), records for circulation patterns described by $700 \mathrm{mb}$ or $500 \mathrm{mb}$ pressure data, such as the PNA index, exist back only to 1947 . These data allow only a short-term assessment of expected extremes and the frequency of recurrence of extremes in circulation index values as indicators of variations in atmospheric circulation patterns.

Even with these limited records, there is evidence for low-frequency variations in circulation. Changes in modes of circulation have been noted by a number of researchers (see Dzerdzeevskii 1969, Kalnicky 1974, Douglas et al. 1982, Webb \& Betancourt 1992), and may be due to the long-term variability in the behavior of atmospheric circulation. For example, it is known that ENSO has approximately a 2 to 6 yr cycle (Diaz \& Pulwarty 1994). Some researchers have found evidence for lower frequency variations as well. This evidence is based on the relatively long record of SOI and SOI reconstructions (e.g. Michaelson 1989, Anderson 1992, Diaz \& Pulwarty 1994), but study results have been inconclusive. Hurrell (1995) suggests that de- cadal changes in circulation and lower tropospheric winter temperatures over the North Atlantic and adjacent areas may be related to NAO. Extended records of circulation indices are needed for a more complete representation of the long-term variability inherent in the natural climate system, and to provide a better temporal context from which to evaluate perceived changes in the present and future.

Tree rings, as proxy data with annual resolution, have been used to reconstruct a number of climate and climate-related variables for many areas of the world, especially in the United States and Europe. Tree rings are also beginning to be used to reconstruct generalized circulation indices, most notably the SOI. The use of circulation indices to explain variations in regional climate has, for the most part, been limited to periods of time for which actual circulation and climate data exist. To date, few attempts have been made to reconstruct circulation indices that are relevant to a particular region to examine the temporal relationships between different circulation features influencing the region. For example, we know ENSO to be an important influence on North American extra-tropical climate. The PNA pattern has been found to be related to this feature at times (Keables 1992). How are these 2 features related over time scales longer than the scarcely 50 yr record that exists?

A logical extension of past research that has investigated regional climate variability and reconstructions of generalized circulation indices is to reconstruct regionally tailored circulation indices that are specific to a particular region. The reconstructed records would offer a way to analyze circulation features that influence the climate of a region and investigate how these various features have interacted with each other, over several hundred years or more. Reconstructions of regionally tailored circulation indices may be used to gain information about low-frequency variations in circulation, and may reveal possible causes for climate variability and extreme events. In this paper, I explore this approach. In the next section, I discuss how indices have been used to describe circulation features, and in the section following, I discuss reconstructions of some circulation indices, using dendrochronological techniques. In the final section, I suggest an application in which a set of regionally tailored circulation indices are compiled for the southwestern United States and reconstructed using dendrochronological techniques.

\section{ATMOSPHERIC CIRCULATION PATTERNS AS DESCRIBED BY INDICES}

Circulation indices have been generated for a variety of purposes. Some have been created to describe a 
certain circulation feature. Others have been compiled as a means to describe and learn something about the influences of circulation on climate in a certain area. Much important information has been derived from studies utilizing these indices, but they are all limited in the time period they cover.

A number of important circulation features have been described by generalized circulation indices. One of the oldest and most well-known circulation indices is the SOI. The SOI is defined simply, although imperfectly, as the difference in standardized pressure between Tahiti and Darwin, Australia (Chen 1982). Other indices that describe the SO have also included measures of precipitation and SST (Michaelson 1989, Wright 1989) but the pressure differences alone compare favorably to the more complex $\mathrm{SO}$ indices when describing conditions in the equatorial Pacific.

Wallace \& Gutzler (1981) defined a number of important winter circulation features teleconnected to North Hemisphere climate (i.e. temporally coincident fluctuations of pressure or other climate parameters in several areas) using a set of generalized indices. This set of indices included: the eastern Atlantic, the Pacific North American, the western Atlantic, the western Pacific, and the Eurasian patterns. The indices describe standing oscillations in mean monthly midtropospheric geopotential height fields at middle and high latitudes of the North Hemisphere in winter. Each of the 5 indices accounts for much of the temporal variance in monthly mean pressure over the regions it influences. Spatially, the group of patterns covers most of the teleconnective relationships inherent in the monthly mean $500 \mathrm{mb}$ height field in the Northern Hemisphere. This set of indices is now used to characterize and track variations in climate, and is published monthly in the Climate Diagnostics Bulletin.

Another family of generalized circulation indices includes those that describe the intensity of zonal transport or contrast zonal with meridional flow. Climate variability and long-term changes in climate have been closely linked to changes between 2 main circulation types characterized by predominantly zonal or meridional flows (Dzerdzeevskii 1969, Lamb 1982). The zonal index (Zl) is one of the most commonly used measures for describing circulation over a specified area and is usually derived by taking the difference between pressure at 2 latitudes (Makrogiannis et al. 1991). A high index value indicates strong zonal flow while a low index value indicates meridional flow (Haltiner \& Martin 1957). Makrogiannis et al. (1991) used mean monthly ZI values over the North Atlantic and Europe to characterize the flow over Europe as predominantly meridional, while finding the flow over the Atlantic to be predominantly westerly, for the period 1873-1988. Inamdar \& Singh (1993) also em- ployed a ZI in their study of the relationship between circulation and rainfall over India during the southwest monsoon season. In this case, they used the difference in surface pressure between a location in central India and one over the southwest tip of India to characterize the general strength of the monsoon flow across the west coast of India. Gruza et al. (1990) used a series of indices that included a measure of zonal transport at $500 \mathrm{mb}$ in their assessment of the power of global indices in predicting regional Northern Hemisphere mean monthly air temperature.

Regionally tailored indices have also been derived. An example of this is the set of indices compiled by Carleton (1987) to describe the Arizona monsoon. Carleton classified $500 \mathrm{mb}$ synoptic types for the summer monsoon season in Arizona from daily satellite data and daily $500 \mathrm{mb}$ maps. He used these classifications to derive an index consisting of the ratio of numbers of wet and dry anticyclones, which indicates the position of the Bermuda high pressure ridge. In his scheme, a more southward position coincides with more frequent dry anticyclones and leads to drier conditions, while a more northerly position coincides with more wet anticyclones and wetter conditions. Yarnal (1993) also presents an example of indices used at smaller synoptic scales in which atmospheric circulation over western Pennsylvania is characterized by pressure pattern intensity and gradient.

Other examples of the derivation and use of both generalized and regionally tailored circulation indices are reviewed by Yarnal (1993). Some of these include indices that describe long-wave patterns over the United States, regional climates of the United States and Canada, troughing and precipitation in the Mediterranean, periodicities in precipitation in Africa, and temperatures in Antarctica based on Southern Hemisphere circulation patterns.

\section{TREE-RING RECONSTRUCTIONS OF INDICES}

A number of studies have investigated the relationships between tree-ring chronologies and atmospheric circulation as described by generalized circulation indices. These studies fall within the field of synoptic dendroclimatology, a term suggested by Hirschboeck et al. (1996) to describe studies that use dated tree rings to reconstruct past records of, and investigate the links between, climate and atmospheric circulation. Hirschboeck et al.'s (1996) review suggests that much of the synoptic dendroclimatological research that is based on circulation indices, to date, has been exploratory, or has merely pointed out the potential of reconstructing generalized circulation indices from tree rings (e.g. Stockton 1990, D'Arrigo \& Jacoby 1991, 
Table 1 Overview of studies related to tree-ring reconstructions of circulation indices

\begin{tabular}{|ll|}
\hline Index & References \\
\hline El Niño/Southern & Michaelson \& Daily (1983) \\
Oscillation (ENSO) & Lough \& Fritts (1985) \\
& Michaelson (1989) \\
& Lough \& Fritts (1990) \\
& Swetnam \& Betancourt (1990) \\
& D'Arrigo \& Jacoby (1991, 1992) \\
& Cleaveland et al. (1992) \\
& Lough (1992) \\
& Meko (1992) \\
& Swetnam \& Betancourt (1992) \\
& Stahle \& Cleaveland (1.993) \\
& Woodhouse (1993) \\
& Stahle (1990) \\
Pacific/North American & Stahle \& Cleaveland (1992) \\
pattern (PNA) & Stahle \& Cleaveland (1996) \\
North Atlantic & Stockton (1990) \\
Oscillation (NAO) & D'Arrigo et al. (1994) \\
& Chbouki et al. (1995) \\
Sea Surface Temper- & Douglas (1976) \\
ature, California/Baja & \\
Subtropical High, Chile & Villalba (1989) \\
\hline
\end{tabular}

1992, Meko et al. 1993). Very few actual reconstructions of circulation indices have been generated. The majority of the research has focussed upon ENSOrelated circulation as it has become recognized as a major factor in the interannual and decadal (or longer) variability of global atmospheric circulation (Diaz \& Pulwarty 1994). Table 1 provides a summary of studies related to tree-ring reconstructions of circulation indices.

\subsection{El Niño/Southern Oscillation}

Lough \& Fritts (1985) first investigated the possibility of reconstructing the SOI from tree rings when they noted that climate reconstructions from trees in western North America (especially for temperature and precipitation) contained an SO signal. They went on to reconstruct the $\mathrm{SO}$ directly from tree rings, using chronologies both in the Southern Hemisphere (Argentina, Chile, Tasmania, New Zealand and South Africa) and western North America, from 1601 to 1963. Western North American chronologies provided the best correlations and explained about $50 \%$ of the variance in SO. They later improved these results slightly, using just the North American tree-ring chronologies and a different version of the SOI (Lough \& Fritts 1990). These tree-ring chronologies were able to explain 57 to $59 \%$ of the variance in winter SOI. Lough (1992) further analyzed this reconstruction for evidence of changes in SOI characteristics over the past 3 centuries. This work demonstrated that tree rings from western North America can be used to explain a significant amount of the variation in SOI. However, such reconstructions are, of course, biased by how the trees in this region record the ENSO signal, which is somewhat different than the signal in the equatorial Pacific.

Michaelson (1989), refining work done by Michaelson \& Daily (1983), reconstructed an ENSO index based on sea level pressure and rainfall in the tropical Pacific and using a set of 7 climatically sensitive and long tree-ring chronologies, primarily located in New Mexico, with a common time period of 1569 to 1965. The principal goal of this study was to examine the changes in amplitude and frequency of ENSO over time. To focus on climate variability in the frequencies characteristic of ENSO, both index and tree-ring series were band filtered before they were compared. A regression model explained $35 \%$ of the variance. Michaelson found that the amplitude and frequency of ENSO events varies over an 80 to 100 yr time scale. The predominant frequency progresses from $10 \mathrm{yr}$ to 3 yr followed by a return to lower frequencies. Amplitude grows as frequency increases with a peak in the 4 to 6 yr range. Less variance in ENSO is explained by Michaelson's model than the variance in SOI explained by the model of Lough \& Fritts (1985), perhaps due to the smaller number of tree-ring chronology sites, which may reflect a more limited regional response of trees to ENSO-influenced climate.

Cleaveland et al. (1992) and Stahle \& Cleaveland (1993) used tree-ring chronologies from the Southern Plains and northern Mexico to reconstruct winter SOI, and to search for multi-decadal-scale changes in the strength and frequency of ENSO events. A regressionbased reconstruction explained $41 \%$ of the variance in winter SOI, and produced a record extending from 1699 to 1971 . Reconstructions based on regression and discriminant function analysis suggest an increase in frequency of winter SOI extremes since 1850. The models used in the reconstructions of winter SOr from Lough \& Fritts (1985) and Cleveland et al. (1992) accounted for 40 to $50 \%$ of the variance in winter SOI. However, the correlation between the 2 series is only $r=0.46(1702-1963)$. This low correlation suggests that although some of the variance explained in the 2 reconstructions is the same (both studies used trees from northern Mexico), a portion of it is different, which is perhaps not surprising, given that climate in western North American is influenced by ENSO in a different way than is the climate in the Southern Plains. The trees reflect these differences, and thus the reconstructions are different.

D'Arrigo \& Jacoby $(1991,1992)$ made a preliminary assessment of the usefulness of New Mexico tree-ring 
chronologies in reconstructing ENSO characteristics. They also examined the feasibility of using the New Mexican chronologies in conjunction with tree-ring records from teak in Java to estimate an ENSO-related SST index (D'Arrigo \& Jacoby 1992). In order to improve proxy records of ENSO, they suggest the development of other tree-ring chronologies and high resolution proxy records, such as corals, varves, and ice cores from ENSO-sensitive areas, with different spatial modes of variability (see Diaz \& Markgraf 1992). A better approach to reconstructing ENSO, if that is the goal, would be to use a combination of proxy records rather than any one type of proxy data from a specific region. This strategy would aid in screening out local and proxy-specific biases in the ENSO signal.

Other work has focussed on ENSO and its impact on tree growth and climate in the western United States by using ENSO-related indices to examine the spatial variability of the signal, and its effect on regional climates and climate-related variables. Meko (1992) investigated the strength of the frequency domain and regional coherence of a band-limited ENSO signal in regional tree-ring chronologies for the western United States. He found the strongest signal in Arizona and New Mexica, but found the signal to be relatively weak in all regions when compared to that of lower frequency fluctuations (wavelengths longer than 20 yr). The study also supported previous evidence of a northsouth opposition of moisture anomalies in the interior western United States as an ENSO signature. In a study of Colorado Front Range trees (Woodhouse 1993), tree growth was found to be an indicator of the strength and sign of the ENSO signal in this transitional area. Cold ENSO events tended to be more consistently recorded in the tree rings, while the warm ENSO (El Niño) events perhaps accounted for more growth extremes. Swetnam \& Betancourt $(1990,1992)$ investigated the effect of ENSO on fire in the southwestern U.S., and its influence as a climatically driven large-scale disturbance factor They found ENSOrelated climate to be a factor in determining fire occurrence and magnitude, as well as more local 'fire weather'.

This excellent collection of research illustrates the usefulness of tree rings in reconstructing ENSOrelated indices and learning more about the long-term behavior of this mechanism, including the spatial and temporal variations in phase, magnitude, and frequency. I suggest, as others have, that if the goal is to reconstruct ENSO indices, it is necessary to use a number of sources of proxy data to control for the individual biases introduced by the type and locale of the proxy data source. On the other hand, if the goal is to determine how ENSO influences climate in a particular region, then these different reconstructions, although perhaps not comparable, are indeed important records of the impact of ENSO on tree growth and climate in that region.

\subsection{Pacific/North American pattern}

The PNA circulation pattern frequently accompanies ENSO events (Yarnal 1985), but it is also a primary mode of winter circulation variability across North America in non-ENSO years (Simmons et al. 1983). This circulation pattern (in the positive sense) is characterized by a strong, deep Aleutian Low, an upper level high over western Canada, and a deep low over the southeastern United States (Yarnal \& Diaz 1986). In a reverse PNA pattern (negative values), the signs of the pressure anomalies are reversed. In general, the areas of the United States most directly affected by PNA circulation are the Southeast and Northwest (Leathers et al. 1991).

Several researchers studying the relationships between tree growth, climate, and circulation patterns in the Southern Plains and southeastern United States have examined the role of PNA in influencing tree growth. Stahle (1990) studied frost rings in post and white oak in the Southern Plains and found these damaged rings to result from anomalously warm winters, and early springs followed by severe cold outbreaks during the spring, an event called a false spring. In the frost ring years for the period of historical record, he found that false springs were associated with cold ENSO events, which tend to co-occur with the reverse PNA circulation pattern. Stahle \& Cleaveland (1992) reconstructed spring rainfall from baldcypress for South Carolina, North Carolina, and Georgia for the last $1000 \mathrm{yr}$. When the reconstructions were correlated with gridded SLP (sea-level pressure) data, the pattern of significant correlations was 'vaguely reminiscent' of a PNA pattern. When the reconstructions were correlated with the actual PNA index (as well as NAO and ENSO indices) there were no significant correlations, possibly due to reconstructions being for the spring, while the indices are more characteristic of winter conditions. In an effort to account for low frequency variance on an expanded set of tree-ring chronologies from the southeastern United States, Stahle \& Cleaveland (1996) looked for a pattern associating treegrowth and Northern Hemisphere $700 \mathrm{mb}$ heights in spring. They found a pattern similar to the PNA pattern, which they used as a basis for a PNA-like index. In a comparison of the correlations between the scores of the first principal component from the 11 tree-ring chronologies and a set of circulation indices, they found that highest correlations existed between the first principal component scores from the tree rings 
and the derived PNA-like index $(r=0.61)$, followed by the PNA index $(r=0.47)$.

In this series of studies cited above, the focus was on trying to determine how large-scale climatic forcing influences climate, and in turn, tree growth. In the southeastern U.S., the PNA pattern is a likely influence, given the geographic regions it most directly affects. It is more of a winter pattern, and the trees in the Southern Plains and the southeastern U.S. reflect spring conditions, so a better match is made with a PNA-like index, tailored for this area. Although this regionally tailored PNA index may not be of use to researchers desiring an extended PNA index, the importance of this index lies in its potential ability to explain variations in the regional climate.

\subsection{North Atlantic Oscillation}

Along with the PNA, the NAO has been identified as one of the 2 most prominent anomaly patterns in the Northern Hemisphere winter (Kushnir \& Wallace 1989). The NAO links conditions in the northern Atlantic and Europe. Its primary characteristics are a negative relationship between winter temperatures in Greenland and Labrador, and in northwestern Europe, and a negative correlation between SLP in the areas of the Icelandic Low and the Azores High (Wallace \& Gutzler 1981, D'Arrigo et al. 1994). Several indices have been used to describe the NAO, including one based on the difference in temperature between Greenland and Norway and one based on the normalized pressure difference between the Icelandic Low and the Azores High (Van Loon \& Rogers 1978, Rogers 1984). Low values of the NAO are characterized by above average pressure near Greenland and below average pressure at the Azores, with warm conditions in western Greenland and cold conditions in the eastern United States and northwestern Europe. An extreme NAO condition arises during the time the pressure gradient between the Icelandic Low and the Azores High reverses (D'Arrigo et al. 1994)

Variations in the NAO are also associated with rainfall in Morocco (Lamb \& Peppler 1987). After reconstructing a $1000 \mathrm{yr}$ record of drought from trees in Morocco, Stockton (1990) suggested that the relationship between tree growth and precipitation might be used to reconstruct a record of the NAO. Chbouki et al. (1995) reconstructed moisture anomaly patterns for Morocco from tree rings and found the strength and position of the Azores High to be one of 3 main factors influential to periods of drought. They suggest that trees in this region have great potential for reconstruction of pressure anomalies, which could possibly be used in NAO prediction.
D'Arrigo et al. (1994) examined the NAO signature in tree-ring records in Scandinavia and Labrador Using superposed epoch analysis, they found positive (negative) growth departures in temperature-sensitive trees from Scandinavia corresponded to negative (positive) anomalies in winter SLP related to the Icelandic Low pressure center. Trees also showed a positive correlation to winter temperatures in Oslo, Norway, a station that defines the northwest European terminus of the winter temperature oscillation. These results indicate the potential usefulness of tree rings in reconstructing atmospheric-oceanic variations in the North Atlantic, such as those described by the NAO index. D'Arrigo et al. (1994) suggest that future work incorporating more tree-ring records and other sources of proxy data could provide information about decadal fluctuations in the North Atlantic climate system in the past.

Although perhaps not as well known, the NAO influences large-scale climate, as does ENSO. Research suggests that NAO extremes may be associated with and/or influence Atlantic SST anomalies, the strength of the Gulf Stream, westerly flow characteristics, and sea ice and icebergs in the Arctic (Rogers \& Van Loon 1979, Rogers 1984, Wallace et al. 1990). There is also evidence that conditions in the North Atlantic during deeper than average Icelandic Lows (high NAO) correspond to positive SLP anomalies in the central North Pacific (Van Loon \& Rogers 1978). In the reconstruction of NAO, there is perhaps an advantage in the use of tree rings over the recon. struction of ENSO-related indices. Trees grow and appear to record the NAO signal in locations that are directly affected by the climatic effects of this oscillation, thus there is a more direct connection than between tree growth and the SOI, and less bias may be introduced by a local filtering of the signal. There are few datable, climatically sensitive tree species that grow in the region where the SO occurs (i.e. the tropical Pacific), though the use of teak in Indonesia is currently being explored (D'Arrigo et al. 1995). One potential problem in obtaining a good NAO reconstruction is that trees at upper latitudes tend to be sensitive to summer temperatures. However, trees from some high latitude sites record climate from other seasons, and the NAO extremes and related anomalies can persist into summer (Rogers \& Van Loon 1979, Jacoby \& D'Arrigo 1989). D'Arrigo et al. (1994) believe that the addition of more tree-ring chronologies and other types of proxy data, such as from ice cores, that are in areas directly influenced by the NAO would be useful for producing good reconstructions of the atmosphere-ocean interactions in the North Atlantic and the climate conditions they influence. 


\subsection{Other indices}

Several other less widely known or regionally tailored atmospheric circulation indices have been reconstructed with tree rings. These studies focus on specific regions and address circulation or circulation-related features that are related to regional climate.

Douglas (1976) explored the use of SST in an index of air-sea interactions off the coast of California and Baja, California. He reconstructed eastern North Pacific SST from 1671 to 1972 using 7 tree-ring chronologies from southern California and western Mexico. The reconstructions explained $53 \%$ of the variance in winter SST, $54 \%$ of the variance in spring, and $55 \%$ of the variance in summer. SST is also related to climate over other parts of the United States, notably the south and central U.S., and is associated with ENSO-related climate variability, so the reconstruction could also provide information about climate variability in those areas (Douglas 1976).

In an examination of circulation patterns in the Southern Hemisphere, Villalba (1989) used tree-ring chronologies in Chile and Argentina to estimate variations in the latitude of a semipermanent subtropical Pacific anticyclone off the Chilean coast. Variations in the north-south position of this anticyclone are related to the strength of the Hadley cell and the meridional temperature gradient, and are important because they influence regional precipitation patterns in Chile and Argentina. Tree-ring widths were correlated with indices related to the position of the anticyclone and to the monthly average latitudinal position of the anticyclone. A set of tree-ring chronologies was used to estimate a record of the position of the anticyclone in summer (1572-1974) and winter (1450-1972).

\section{REGIONALLY TAILORED INDICES AND RECONSTRUCTIONS}

Generalized circulation indices provide descriptions of large-scale circulation features. Good proxy records of important circulation features, such as the Southern Oscillation and the North Atlantic Oscillation, are of great value, and improvements on these reconstructions are continuing to be made. These features have wide-reaching impacts on climates in many parts of the world and reconstructed records of their behavior have application in many areas of research. However, a reconstructed generalized circulation index that reflects the behavior of a circulation pattern in one geographical region may not be useful when applied to a different region. An SOI reconstructed from trees in the southwestern United States is different from one reconstructed from trees in the Southeast because the effect of ENSO on climate is different in these 2 regions, but both reconstructions will provide information about how ENSO influences climate in these particular regions. Additionally, there may be indices that are more appropriate for describing region-specific influences of major circulation features. For example, in examining how ENSO influences North American climate, Murphree (1996) suggests that there are other indices more directly related to extra-tropical climate than the SOI that may be more useful, such as the 200 hPa zonal wind index.

I suggest an aiternative approach to the use and reconstruction of generalized circulation indices. To understand how circulation features influence regional climates, regionally tailored indices, as opposed to generalized indices, may be used to describe the circulation patterns that are important to a specific region. Proxy data may be used not only to reconstruct generalized indices (as in improving the SOI), but also to reconstruct regionally tailored indices that describe circulation patterns that are important to climate in a particular area of interest. A set of regionally tailored circulation indices must first be generated that describes features that are important to the area of interest. This set of indices can include indices specifically constructed to describe circulation features that influence the climate of a particular region, but can also include indices such as the SOI and PNA index. The second type of indices is included if they are influential to the climate in the region of interest, but the goal of the reconstruction of these indices is to help explain regional climate variations, not to reconstruct the large-scale circulation features described by the generalized indices. Next, it must be determined if it is possible to obtain good reconstructions of these indices. If this can be accomplished, the reconstructions can then be used to investigate how circulation patterns interact with each other over the length of the reconstructions and inferences may be made about how they influence variability and extremes in climate.

\subsection{Example from the southwestern U.S. for winter climate}

The southwestern United States is an arid region that, in winter, lies south of the usual storm track of the westerlies and north of the low-latitude flow of tropical air across Mexico. Generally, high pressure dominates the region in winter and only anomalous conditions steer storms into the area and bring large amounts of precipitation (Sellers \& Hill 1974). In fall and winter, the region can be influenced by ENSO, although the impacts are variable from event to event. Other large-scale features, such as the PNA circula- 
tion pattern, may have important influences on winter climate as well.

The Southwest has long been a focus of dendroclimatological studies, largely due to the presence of long-lived and climatically sensitive trees in this arid environment. A great number of excellent chronologies have been developed for this region. Eighty-eight tree-ring chronologies for the common time period 1701 to 1983 exist for an area including southern California, southern Nevada, northern Baja, Arizona, and western New Mexico.

The climatic characteristics of the Southwest, in concert with the availability of tree-ring chronologies from climatically sensitive trees, make this a suitable region for the investigation of potential reconstructions for circulation indices. In the arid Southwest, the study of past variations and extremes in climate and impacts on climate is important because this area is currently experiencing growth that may be pushing the limits of resources. Information about past climate and how it may have been influenced by atmospheric circulation features may provide clues to how perturbations in regional atmospheric circulation patterns induced by global climate change may influence winter climate in the desert Southwest.

In this study, the objectives I wish to achieve include determining which atmospheric circulation patterns are influential to winter climate in the Southwest, compiling a set of circulation indices using observed data that describe these patterns, using tree-ring chronologies to reconstruct these circulation indices, and finally, determining how the relationships between these reconstructed circulation indices have varied over time. I define winter climate in terms of average maximum winter temperature and number of rainy days (days with a trace or more of precipitation recorded) for the winter wet season (NovemberMarch). The study region encompasses southern California and Nevada, Arizona, and western New Mexico (Fig. 1).

I first identified the large-scale circulation features important to winter climate in the Southwest, and collected and/or generated a set of indices describing these features (Table 2) (Woodhouse in press). Briefly, the set of indices included: 2 ENSO-related indices (SST and SOI indices), a modified PNA index, and 2 indices that feature the strength of a $500 \mathrm{mb}$ low over the Southwest. Of these last 2 indices, one was based on the low in combination with $500 \mathrm{mb}$ highs over the Gulf of Alaska and the Great Lakes (SWTROF), and the other was based on the low in conjunction with the latitudinal position of a Pacific Ocean high (PHSWL).

I then used a set of 88 tree-ring chronologies, located within the study area, to investigate the feasibility of reconstructing the circulation indices. A standard

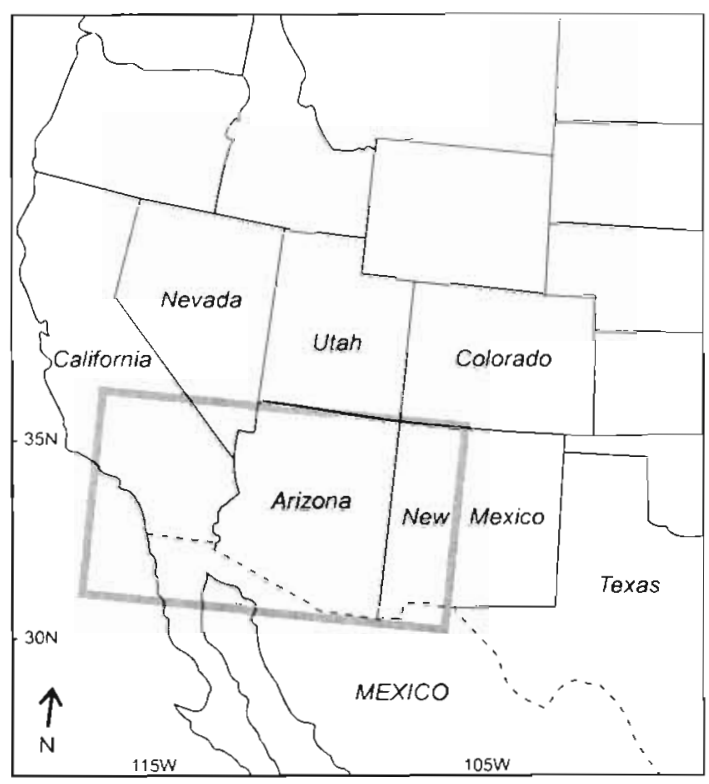

Fig. 1. Location of study area in the southwestern U.S.

reconstruction technique of principal components regression (Cook \& Kairiukstis 1990) was used to produce the models used to generate reconstructions of the circulation indices. Model results were evaluated and assessed using a standard set of calibration and verification statistics (Fritts 1976). The adjusted explained variances for the regression models ranged from $26 \%$ (winter SST) to $78 \%$ (SWTROF, winter average), and all calibration/verification statistics were significant at $\alpha=0.01$. The reconstructions were produced from the models and validated with historical ENSO records, other dendrochronological reconstructions of SOI, and actual and reconstructed SLP patterns for western North America (Fritts 1991).

Preliminary analyses of the reconstructions suggested some temporal variations in the behavior of these reconstructed indices. In a rotated principal components analysis of the circulation indices from observed data (1947-1990), the indices fell into 2 groups. One group contained the ENSO indices and the modified PNA index, and the other contained the 2 southwestern low indices, SWTROF and PHSWL. In an analysis of the reconstructed indices (1702-1983) results suggested 3 groupings of indices. The first group was the same as that yielded from the observed data, but the SWTROF index formed a second component, and the PHSWL index fell into a third component. These results imply that the relationships between these indices in the short term may be different than in the past 3 centuries. Frequency counts of the numbers of years of extreme values (i.e. the upper and lower $20 \%$ of values) for each reconstructed index were com- 
Table 2. Circulation indices used in this study. Z: standardized $500 \mathrm{mb}$ helght at each grid point

\begin{tabular}{|c|c|c|c|}
\hline Index & Description & Source & Interval \\
\hline SOI & $\begin{array}{l}\text { Southern Oscillation Index: SLP difference, } \\
\text { Tahiti - Darwin }\end{array}$ & $\begin{array}{l}\text { Climate Prediction Center (CPC), } \\
\text { Washington, DC, USA. }\end{array}$ & $\begin{array}{l}\text { Winter }(D J F) \\
\text { fall-winter }(S-F)\end{array}$ \\
\hline SST & $\begin{array}{l}\text { Sea surface temperature from COADS (comprehensive } \\
\text { Ocean-Atmosphere Data Set) data } \\
4^{\circ} \mathrm{N}-4^{\circ} \mathrm{S}, 160^{\circ}-80^{\circ} \mathrm{W}(1930-1979) \\
5^{\circ} \mathrm{N}-5^{\circ} \mathrm{S}, 190^{\circ}-90^{\circ} \mathrm{W}(1980-1990)\end{array}$ & $\begin{array}{l}\text { Kiladis \& Diaz (1989) } \\
\text { CPC Niño3 index }\end{array}$ & Winter (DJF) \\
\hline $\begin{array}{l}\text { PNA- } \\
\text { modified }\end{array}$ & $\begin{array}{l}\text { Pacific North American patterns; a measure of } \\
\text { zonality across North America. Location of pressure } \\
\text { centers modified after Keables (1992) PNA3 } \\
\text { pattern. } \\
\begin{aligned} \text { PNA }= & {\left[-Z\left(135^{\circ} \mathrm{W}, 35^{\circ} \mathrm{N}\right)+Z\left(100^{\circ} \mathrm{W}, 75^{\circ} \mathrm{N}\right)\right.} \\
& \left.-Z\left(70^{\circ} \mathrm{W}, 30^{\circ} \mathrm{N}\right)\right] / 3\end{aligned}\end{array}$ & Woodhouse (in press) & Winter (JFM) \\
\hline SWTROF & $\begin{array}{l}\text { Southwestern trough; measure of intensity of low } \\
\text { over the SW, in combination with high pressure } \\
\text { over the Gulf of Alaska and the Great Lakes. } \\
\begin{aligned} \text { SWTROF }= & {\left[-Z\left(140^{\circ} \mathrm{W}, 50^{\circ} \mathrm{N}\right)+Z\left(115^{\circ} \mathrm{W}, 35^{\circ} \mathrm{N}\right)\right.} \\
& \left.-Z\left(80^{\circ} \mathrm{W}, 45^{\circ} \mathrm{N}\right)\right] / 3\end{aligned}\end{array}$ & Woodhouse (in press) & $\begin{array}{l}\text { Winter wet } \\
\text { season (Nov- } \\
\text { Mar), and NDM }\end{array}$ \\
\hline PHSWL & $\begin{array}{l}\text { Pacific high/Southwestern low; measure of } \\
\text { intensity of low over the SW, in conjunction with } \\
\text { the longitudinal position of the Pacific high. } \\
\begin{aligned} \text { PHSWL }= & Z\left(115^{\circ} \mathrm{W}, 35^{\circ} \mathrm{N}\right)-\text { longitude of the greatest } \\
& 500 \mathrm{mb} \text { height at } 30^{\circ} \mathrm{N}, 120^{\circ}-160^{\circ} \mathrm{W}\end{aligned}\end{array}$ & Woodhouse (in press) & $\begin{array}{l}\text { Winter wet } \\
\text { season (Nov- } \\
\text { Mar), and NDM }\end{array}$ \\
\hline
\end{tabular}

piled by century. Although many of the years of extreme values appeared to be evenly distributed over the 3 centuries, the SOI showed a marked increase in years of extreme values in the 20th century, years of extreme PNA values were more frequent in the 18th and 19 th centuries, and SWTROF extreme-year values (dry years only) occurred most often in the 19th century (Woodhouse 1996).

Because there appears to be evidence for long-term changes in the circulation features that influence Southwestern climate, it may be reasonable to expect these types of changes to persist in the future. Given an understanding of the way circulation patterns influence regional climates, information about past relationships between circulation indices may be used to help explain the variations in climate we detect in the present and future.

\section{CONCLUSIONS}

There is a need for a better understanding of how large-scale circulation features influence regional climates on decadal to longer time scales. Instrumental records of both climate and circulation variables are usually not greater than $100 \mathrm{yr}$, and more commonly are much shorter. The lengths of these records are inadequate for assessing decadal-scale variations and the frequencies of extremes that may be expected to occur. This review reveals the many types of generalized circulation indices used to describe atmospheric circulation patterns, as well as the potential to develop regionally tailored indices. Proxy data, such as those from tree rings, can be used to extend records of circulation indices. An increasing number of generalized circulation index reconstructions are being generated from tree rings. I suggest the potential exists for studies that utilize reconstructions of regionally tailored circulation indices that describe circulation features important to regional climates, spatially and temporally. In the example from the Southwest, I demonstrated how tree-ring chronologies can be used to reconstruct a set of circulation indices that were designed to describe the important circulation features influencing winter climate. In this study, I fulfilled my stated objectives by defining and compiling a set of 5 regionally tailored indices that describe circulation features influential to winter climate in the Southwest, reconstructing these indices with tree-ring chronologies, and examining how the relationships between these reconstructed circulation indices varied over the past 3 centuries.

The potential exists to apply this research approach in a variety of geographic areas at different spatial scales, and incorporating different types of proxy data. Nonetheless, there are limitations that should be considered. In using any sort of proxy data to reconstruct 
past climate, only a portion of the total variance of the observed data will be explained by the proxy data. For the study described above, the collection of tree-ring chronologies was able to explain between 26 and $78 \%$ of the variance in the circulation indices. The trees in the southwestern United States are among the most climatically sensitive in the world, but even so, there are portions of the variability in climate and circulation that are not duplicated in the tree-ring reconstructions. An additional difficulty is related to the verification of reconstructed circulation indices using independent data. There are few proxies for $500 \mathrm{mb}$-based circulation indices that can provide independent confirmation for the period of the reconstructions. Reconstructions from other types of proxy data could provide additional verification.

Atmospheric circulation features have important impacts on regional climates throughout the world Regional climate change, whether due to anthropogenic, internal, or external forcing factors, may have increasingly greater effects on human activities, especially in view of continued economic development and population increases. Thus, a better understanding of how global- to regional-scale changes in circulation patterns may influence regional climates is vital. This knowledge is obtainable through continued and innovative research utilizing proxy data, such as tree rings, in collaboration with other types of proxy data and modeling techniques.

Acknowledgements. The funding for this research was provided by National Park Service grant no. 8012-2-9001. I thank Katherine Hirschboeck for her helpful comments and sugges. tions on preliminary versions of the manuscript. I also thank Dave Stahle for his helpful and constructive comments and recommendations, as well as those of an anonymous reviewer

\section{LITERATURE CITED}

Anderson RY (1992) Long-term changes in the frequency of occurrences of El Nino events. In: Diaz HF, Markgraf V (eds) El Nino: historical and paleoclimatic aspects of the southern oscillation. Cambridge University Press, Cambridge, p 193-200

Barnston AG, Livezey RE (1987) Classification, seasonality, and persistence of low-frequency atmospheric circulation patterns. Mon Weather Rev 115:1083-1126

Carleton AM (1987) Summer circulation climate of the American Southwest, 1945-1984. Ann Assoc Am Geogr 77:619-634

Chboukı N, Stockton CW, Myers DE (1995) Spatio-temporal patterns of drought in Morocco. Int J Climatol 15:187-205

Chen WY (1982) Assessment of southern oscillation sea-level pressure indices. Mon Weather Rev 1 10:800-807

Cleaveland MK, Cook ER, Stahle DW (1992) Secular variability of the Southern Oscillation detected in tree-ring data from Mexico and the southern United States. In: Diaz HF, Markgraf $V$ (eds) El Nino: historical and paleoclimatic aspects of the southern oscillation. Cambridge University Press, Cambridge, p 271-291

Cook ER, Kairiukstis LA (1.990) Methods of dendrochonology: applications in the environmental sciences. Kluwer Academic Publishers, Dordrecht
D'Arrigo RD, Cook ER, Jacoby GC, Briffa KR (1994) NAO and sea surface temperature signatures in tree-ring records from the North Atlantic sector. Quat Sci Rev 12:431-440

D'Arrigo RD, Jacoby GC (1991) A 1000-year record of winter precipitation from northwestern New Mexico, USA: a reconstruction from tree-rings and its relationship to El Nino and the Southern Oscillation. Holocene 1:95-10.1

D'Arrigo RD, Jacoby GC (1992) A tree-ring reconstruction of New Mexico winter precipitation and its relation to $E$ l Niño/Southern Oscillation events. In: Diaz HF, Markgraf $V$ (eds) El Niño: historical and paleoclimatic aspects of the southern oscillation. Cambridge University Press, Cambridge, p 243-257

D'Arrigo RD, Jacoby GC, Krusic PJ (1995) Progress in dendroclimatic studies in Indonesia. In: Sheu DD, Bradley RD, Wang WC (eds) High resolution records of past climate from monsoon asia: the last 2000 years and beyond. Terr Atmos Oceanic Sci 5:349-363

Diaz HF, Kiladis GN (1992) Atmospheric teleconnections associated with the extreme phases if the Southern Oscillation. In: Diaz HF, Markgraf V (eds) El Niño: historical and paleoclimatic aspects of the southern oscillation. Cambridge University Press, Cambridge, p 2-28

Diaz HF, Markgraf V (eds) (1992) El Niño: historical and paleoclimatic aspects of the southern oscillation. Cambridge University Press, Cambridge

Diaz HF, Pulwarty RS (1994) An analysis of the time scales of variability in centuries-long ENSO-sensitive records in the last 1000 years. Clim Change 26:317-342

Douglas AV (1976) Past air-sea interactions over the eastern North Pacific Ocean as revealed by tree-ring data. PhD dissertation, University of Arizona, Tucson

Douglas AV, Cayan DR, Namias J (1982) Large-scale changes in North Pacific and North American weather patterns in recent decades. Mon Weather Rev 110:1851-1862

Dzerdzeevskii BL (1969) Climatic epochs in the twentieth century and some comments on the analysis of past climates. In: Wright HE (ed) Quaternary geology and climate, Vol 16 of the Proceedings of the 7 th Congress, International Association of Quaternary Research, Washington, DC, p 49-60

Fritts HC (1976) Tree rings and climate. Academic Press, New York

Fritts HC (1991) Reconstructing large-scale climatic patterns from tree-ring data. University of Arizona. Tucson

Gruza GV, Ran'kova EYa, Semenyuk EA (1990) Relationship between atmospheric circulation indices and surface air temperature in the Northern Hemisphere. Sov Meleorol Hydrol 6:13-20

Haltiner GJ, Martin FL (1957) Dynamical and physical meteorology. McGraw-Hill Publishers, London

Hirschboeck KH, Ni F, Wood ML, Woodhouse CA (1996) Synoptic dendroclimatology: overview and outlook. In: Dean JS, Meko DM, Swetnam TW (eds) Tree rings, environment, and humanity. Radiocarbon, Tucson, p 205-223

Hurrell JW (1995) Decadal trends in the North Atlantic Oscillation: regional temperature and precipitation. Science 269 $676-679$

Inamdar SR, Singh SV (1993) Relationship between circulation and rainfall over India during the southwest monsoon season, Part II, 700hPa contour height field and some synoptic indices. Theor Appl Climatol 48:1-14

Jacoby GC, D'Arrigo RD (1989) Reconstructed northern hemisphere annual temperature since 1671 based on high-latitude tree-ring data from North America. Clim Change 14 $39-59$

Kalnicky RA (1974) Climatic change since 1950. Ann Assoc Am Geogr 64:100-112 
Keables MJ (1992) Spatial variability of midtropospheric circulation patterns and associated surface climate in the United States during ENSO winters. Phys Geogr 13:331-348

Kiladis GN, Diaz HF (1986) An analysis of the 1877-78 ENSO episode and comparison with 1982-83. Mon Weather Rev 114:1035-1047

Kiladis GN, Diaz HF (1989) Global climatic anomalies associated with extremes of the Southern Oscillation. J Clim 2: $1069-1090$

Kushnir J, Wallace JM (1989) Low-frequency variability in the Northern Hemisphere winter J Atmos Sci 46:3122-3142

Lamb HH (1982) Climate change, history, and the modern world. Methuen, New York

Lamb PJ, Peppler RA (1987) North Atlantic Oscillation: concept and an application. Bull Am Meteorol Soc 68:1218-1225

Leathers DL, Yarnal B. Palecki MA (1991) The Pacific/North American teleconnection pattern and United States climate, Part $L$, regional temperature and precipitation associations. J Clim 4:517-528

Lough JM (1992) An index of the Southern Oscillation reconstructed from western North American tree-ring chronologies. In: Diaz HF, Markgraf V (eds) E] Niño: historical and paleoclimatic aspects of the southern oscillation. Cambridge University Press, Cambridge, p 215-226

Lough JM, Fritts HC (1985) The Southern Oscillation and tree rings: 1600-1961. J Clim Appl Meteorol 24:952-966

Lough JM, Fritts HC (1990) Historical aspects of El Niño/ Southern Oscillation-information from tree rings. In: Glynn PW (ed) Elsevier Oceanography Series 52: Ecological consequences of the 1982-85 El Nino. Elsevier Science Publishers, A.msterdam, p 285-321

Makrogiannis TJ, Sahsamanoglou HS, Flocas AA, Bloutsos AA (1991) Analysis of the monthly zonal index values and long-term changes of circulation over the North Atlantic and Europe. Int J Climatol 11:493-503

Meko DM (1992) Spectral properties of tree-ring data in the United States as related to El Niño/Southern Oscillation. In: Diaz HF, Markgraf V (eds) El Niño: historical and paleoclimatic aspects of the southern oscillation. Cambridge University Press, Cambridge, p 227-241

Meko DM, Cook ER, Stahle DW, Stockton CW, Hughes MK (1993) Spatial patterns of tree-growth anomalies in the United States and southeastern Canada. J Clim 6:1773-1786

Michaelson $\mathrm{J}$ (1989) Long-period fluctuations in El Niño amplitude and frequency reconstructed from tree rings. In: Peterson DH (ed) Aspects of climate varnability in the Pacific and Western Americas. Geophysical Monographs 55. American Geophysical Union, Washington, DC, p 69-74

Michaelson J, Daily JT (1983) Long-period modulation of El Niño. In: Proceedings of the eighth climate diagnostics workshop. US Department of Commerce, Washington, DC, p $140-147$

Murphree T (1996) The large scale context for recent precipitation extremes in western North America In: Thirteenth annual Pacific Climate (PACLIM) workshop (abstracts). Asilomar Conference Center, Pacific Grove, CA, April 14-17, 1996. California Dept of Water Resources, Sacramento

Rogers JC (1984) The association between the North Atlantic Oscillation and the Southern Oscillation in the Northern Hemisphere. Mon Weather Rev 112:1999

Rogers JC, Van Loon H (1979) The seesaw in winter temperatures between Greenland and Northern Europe, Part II, Some oceanic and atmospheric effects in middle and high latitudes. Mon Weather Rev 107:509-519

Sellers WD, Hill RH (1974) Arizona climate 1931-1972, 2nd edn. University of Arizona Press, Tucson, AZ
Simmons AJ, Wallace JM, Branstator GW (1983) Baratropic wave propagation and instability, and atmospheric teleconnection patterns. J Atmos Sci 40:1363-1392

Stahle DW (1990) The tree-ring record of false spring in the southcentral USA. PhD Dissertation, Arizona State University, Tempe

Stahle DW, Cleaveland MK (1992) Reconstruction and analysis of spring rainfall over the southeastern U.S. for the past 1000 years. Bull Am Meteorol Soc 73:1947-1961

Stahle DW, Cleaveland MK (1993) Southern Oscllation extremes reconstructed from tree rings of the Sierra Madre Occidental and southern Great Plains. J Clim 6 : $129-140$

Stahle DW. Cleaveland MK (1996) Large-scale climatic influences on baldcypress tree growth across the southeastern United States. In: Jones PD, Bradley RS, Jousel J (eds) Climate variations and forcing mechanisms for the last 2000 years. NATO ASI Series, Series 1, Vol 41. Springer, Berlin, p 125-140

Stockton CW (1990) Climatic, hydrologic, and water supply inferences from tree rings. Civ Eng Practice 5:37-51

Swetnam TW, Betancourt JL (1990) Fire-Southern Oscillation relations in the southwestern United States. Science 249 $1017-1020$

Swetnam TW. Betancourt JL (1992) Temporal patterns of El Nino/Southern Oscillation-wildfire teleconnections in the southwestern United States. In: Diaz HF, Markgraf V (eds) El Niño: historical and paleoclimatic aspects of the southern oscillation. Cambridge University Press, Cambridge, p 259-270

Van Loon H, Rogers JC (1978) The seesaw in winter tempera tures between Greenland and Northern Europe, Part I. General description. Mon Weather Rev 106:296-310

Villalba R (1989) Latitude of the surface high-pressure belt over western South America during the last 500 years as inferred from tree-ring analysis. In: Rabassa J (ed) Quaternary of South America and Antarctic Peninsula. AA Balkema Publishers, Rotterdam, p 273-303

Walker GT, Bliss EW (1932) World Weather V. Mem. R Meteorol Soc 4:53-84

Wallace JM, Gutzler DS (1981) Teleconnections in the geopotential height field during the Northern Hemisphere winter. Mon Weather Rev 109:184-812

Wallace JM, Smith C, Jaing Q (1990) Spatial patterns of atmosphere-ocean interaction in the northern winter J Clim 3:990-998

Webb RH, Betancourt JL (1992) Climatic variability and flood frequency of the Santa Cruz River, Pima County, Arizona. US Geological Survey Water Supply Paper 2379, Reston, VA

Woodhouse CA (1993) Tree-growth response to ENSO events in the central Colorado Front Range. Phys Geogr 14 $417-435$

Woodhouse CA (1996) Climate variability in the southwestern united states as reconstructed from tree-ring chronologies. PhD Dissertation, The University of Arizona, Tucson

Woodhouse CA (in press) Winter climate and atmospheric circulation patterns in the Sonoran Desert region, U.S.A. Int J Climatol

Wright PB (1989) Homogenized long-period Southern Oscillation indices. J Climatol 9:33-54

Yarnal B (1985) Extratropical teleconnections with El Niñof Southern Oscillation events. Prog Phys Geogr 9:315-352

Yarnal B (1993) Synoptic climatology in environmental analysis: a primer. Belhaven Press, London

Yarnal B, Diaz HF (1986) Relationships between extremes of the Southern Oscillation and the winter climate of the Anglo-American Pacific coast. J Climatol 6:197-219 